\title{
Modal Analysis of the Printed Circuit Board Based on Finite Element Method
}

\author{
Ren Guoquan ${ }^{1}$, Li Ben ${ }^{1,2}$, Li Dongwei ${ }^{1}$, Jiao Yingqi ${ }^{1}$ \\ ${ }^{1}$ Ordnance Engineering College, Shijiazhuang Hebei 050003, China \\ ${ }^{2}$ Troops 63981, Wuhan Hubei 430000, China \\ yingqijiao@qq.com
}

Keywords: PCB; finite element; experiment modal analysis; parameter identification

\begin{abstract}
The printed circuit board (PCB) plays a vital role in modern electrical equipment and its reliability will affect electrics greatly. In order to study the vibration characteristics of the PCB, to guarantee its reliability, the finite element model of the PCB is established in ANSYS for the theory of modal analysis. Then, use the modal parameter identification technology to experiment modal analysis. The theoretical and experimental results are basically consistent. Under the premise of the correct model, quantitative analysis of the impact of a PCB thickness to its natural frequency is made in ANSYS. The research results show that the natural frequency of the PCB increases with the increase of the thickness, and the higher order leads to the faster growth, which will provide a reference for the PCB designing.
\end{abstract}

\section{Introduction}

Electronic equipment in use process inevitably subject to vibration and impact, in such a harsh environment, the reliability of electronic equipment will be affected by a lot. According to statistics, in the environmental cause of airborne electronic equipment failure, vibration factors accounted for about $27 \%$. So the dynamic characteristic of the electronic equipment has been paid attention to by the people ${ }^{[1]}$. Printed circuit board (PCB) as the key part in electronic devices, if by dynamic load is bigger, or although is not big, but the frequency of the force and the structure of a certain natural frequency approaches, will produce strong resonance circuit module, which lead to high dynamic stress, strength of structure damage or not allowed deformation ${ }^{[2][3]}$. So this article respectively to the target PCB for theoretical and experimental modal analysis. Theoretical modal analysis by finite element method, ANSYS software for solving the modal frequency and vibration mode; Experimental modal analysis with the aid of experimental equipment test system setup, using modal parameter identification technology to solve the modal frequency and vibration mode. Comparisons show that the correctness of the finite element model in ANSYS, based on the quantitatively discusses the PCB thickness on its natural frequency.

\section{The analysis process of Theoretical modal analysis}

\subsection{The establishment of The target PCB finite element model}

About there are mainly five kinds of finite element modeling method of printed circuit boards, based on the precision and solve the time consideration, this paper adopts the fourth kind of modeling method, such as local to emulate.

The size of the target PCB is $232 \mathrm{~mm} \times 160 \mathrm{~mm} \times 3.5 \mathrm{~mm}$. The material parameters are shown in table 1 .

Tab.1 Circuit board material parameters

\begin{tabular}{cccc}
\hline Materials & Density $\left(\mathrm{kg} / \mathrm{m}^{3}\right)$ & Modulus of elasticity $(\mathrm{MPa})$ & Poisson's ratio \\
\hline The base plate FR-4 & 1900 & $1.11 \mathrm{E}+10$ & 0.28 \\
Aluminum plate & 2780 & $7.0 \mathrm{E}+10$ & 0.3 \\
components & 2000 & $3.25 \mathrm{E}+10$ & 0.3 \\
\hline
\end{tabular}


According to the geometry size and various material parameters, in the ANSYS finite element model is set up as shown in figure 1 .

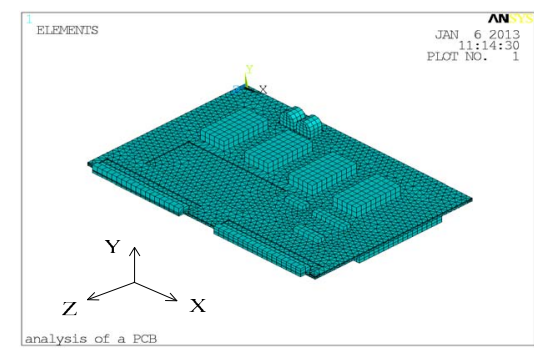

Fig.1 The finite element model of target PCB

\subsection{The analysis results of Theoretical modal analysis}

In ANSYS to the target PCB with full freedom of the constraints of the way. This case, the PCB will have six degrees of freedom rigid body with zero frequency, and the results of the analysis also shows that the first six order modal frequency approximate to zero. Remove the rigid body modes and frequencies, PCB target is obtained under free state in the first four order (removal of rigid-body freedom) natural frequencies and corresponding vibration modes as shown in table 2 .

\section{The analysis process of experiment modal analysis}

\subsection{The equipment and composition of experiment test system}

Experiments, the main equipment used by powerful hammer (for excitation circuit board), the force sensor (pick up excitation signal), acceleration sensor response signal (pick), data collection and analysis system, analysis the signal data (acquisition), the modal analysis software (modal analysis processing), specimens (PCB) ${ }^{[4]}$. The whole test system block diagram is shown in figure 2 .

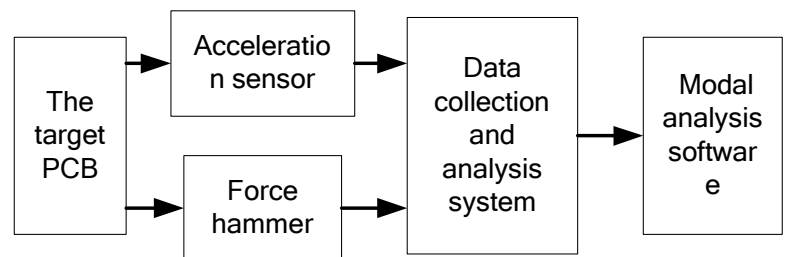

Fig.2 Test system diagram

\subsection{The experiment modal analysis of the target PCB}

\subsubsection{The division of the grid}

Modal experiments by hammering method, the choice of hit points and response points is very important, the choosing principle of hit points is easy tapping force to the structure of each part in order to effectively excites each order modal structure. Response point location and the number of choice mainly depends on the number of sensors are available, the structure of regional, the selected frequency range and the number of the desired mode. In addition, the response points evenly distributed in the structure is a good method, it can reduce the probability of miss modal, and obtain good results.

According to the above analysis, we on incentive points and response points meshing is shown in figure 3 .

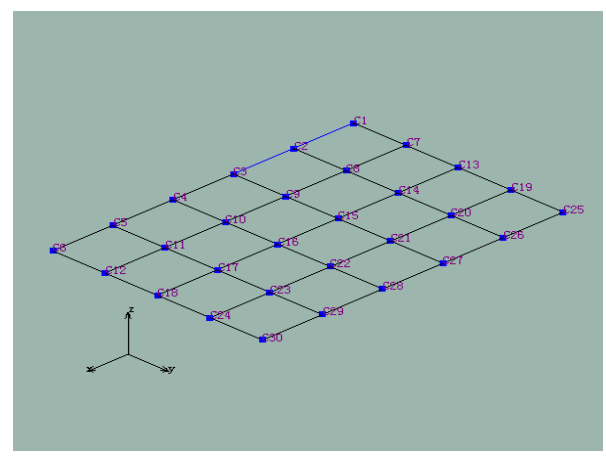

Fig.3 The experimental modal meshing of the target PCB 


\subsubsection{Data analysis and parameter extraction}

${ }^{[5]}$ The measured 30 FRF function import modal analysis software for modal parameters. Parameter identification using polynomial fitting calculation as a whole. The final experiment modal analysis results are shown in table 2.

\subsubsection{Modal quality inspection}

To test the validity of the Modal analysis results, the most effective method is by calculating Modal confidence Criterion (Modal Assurance Criterion, for short) to check each order Modal orthogonality.

MAC is used to measure two different analysis methods to get the modal vibration mode is an effective method of the relativity of, this method can provide a clear representation of two groups of data correlation. Modal definition of sexual norms for,

$$
M A C=\frac{\left|\left\{\varphi_{n}\right\}^{T}\left\{\varphi_{k}\right\}\right|^{2}}{\left|\left\{\varphi_{n}\right\}^{T}\left\{\varphi_{n}\right\}\right| \times\left|\left\{\varphi_{k}\right\}^{T}\left\{\varphi_{k}\right\}\right|}
$$

In the type, $\left\{\varphi_{n}\right\} 、\left\{\varphi_{k}\right\}$ Respectively means the $\mathrm{m}$ and $\mathrm{k}$ modal vibration mode. The basic theory of modal analysis shows that only the same modal of MAC value is 1 , the rest of the order modal MAC orthogonal, its value should be zero. Figure 4 is the modal analysis results of MAC histogram. The figure shows between order modal and the other basic orthogonal (except the order MAC value between 3 and 4 larger). Show that the modal analysis and parameter extraction result is valid.

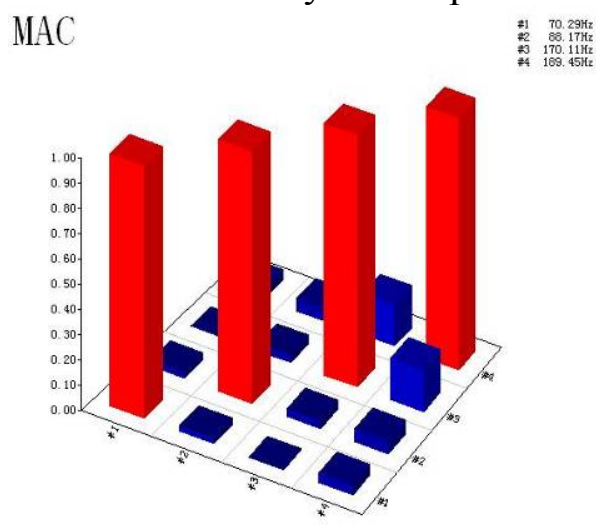

Fig.4 The histogram of MAC

\section{Comparison and analysis}

Using the theory of finite element method (FEA) of modal analysis results with the experimental modal analysis (EMA) result list as follows,

Tab. 2 The results contrast table between theoretical modal analysis and experiment modal analysis

\begin{tabular}{ccccc}
\hline Order & $\begin{array}{c}\text { FEA } \\
(\mathrm{Hz})\end{array}$ & Vibration mode & $\begin{array}{c}\text { frequency } \\
(\mathrm{Hz})\end{array}$ & $\begin{array}{c}\text { EMA } \\
\text { Vibration mode }\end{array}$ \\
\hline \\
\hline
\end{tabular}




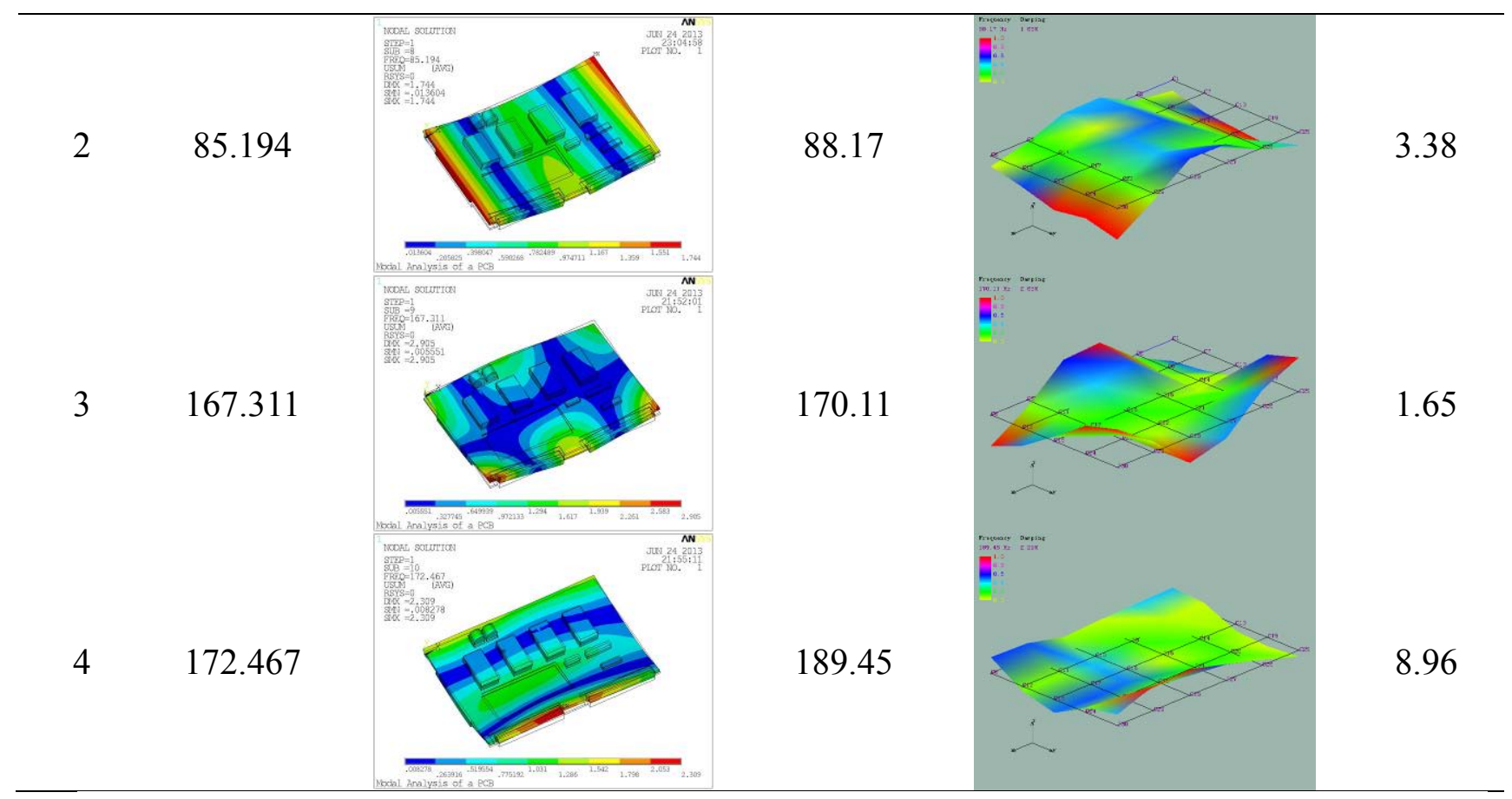

Proceeds from table 2, the FEA modal vibration mode and EMA income basic similar, and each order natural frequency is very close, the maximum relative error occurred to the fourth order, $8.96 \%$. Through the comparison of the two, can test the validity of the theoretical modeling, which can improve the modeling method, for a more accurate theory of modal analysis to lay a solid foundation. So in the future research, the modal analysis of the vibration reliability of simple you can try to use the computer simulation of modal analysis method, to avoid the complex operation, instrument is expensive, time consuming, experimental modal analysis method.

\section{The influence of thickness on the natural frequency}

Convenience of PCB modal analysis based on ANSYS, in ensuring the basic model on the basis of correctly, on the base plate thickness of $2.5 \mathrm{~mm}, 2.6 \mathrm{~mm}$ and $2.7 \mathrm{~mm}, 2.8 \mathrm{~mm}$ and $2.9 \mathrm{~mm}, 3.0$ $\mathrm{mm}$ and $3.5 \mathrm{~mm}, 4.0 \mathrm{~mm}$ and $4.5 \mathrm{~mm}$ PCB has carried on the simulation analysis, the analysis result is shown in figure 5 .

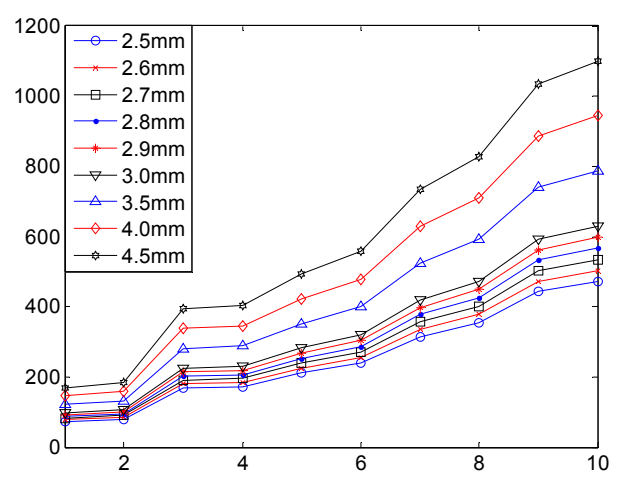

Fig.5 Each order natural frequency with the PCB thickness variation

From the figure, each order natural frequency of PCB thickness increases with the increasing of the plate, and with higher order time, frequency increases, the more obvious. Would be based on this, by increasing the thickness of the circuit board to improve its natural frequency, to ensure the reliability of electronic equipment. In addition, also can through the circuit boards to other metal materials, to improve the natural frequency, by increasing the stiffness is limited by space, should not be discussed here. 


\section{Conclusion}

In this paper, by using ANSYS software to establish finite element model of PCB, theoretical modal analysis, get the vibration mode and natural frequency of circuit board; Then designs the experimental modal analysis, the use of modal parameter identification technology is used to identify the parameters, compared with the results of FEA and EMA, the following conclusions:(1) whether it is a natural frequencies in both or all of the order modal is good, each other, both prove the validity of the finite element model, and shows the rationality of the experimental modal analysis;(2) FEA on the whole, the inherent frequency is EMA from natural frequency numerical small (except for the first order), the reason may be that affect local various components on printed circuit boards, and, in turn, affects the natural frequency of the circuit board and the finite element model does not take into account local modeling. In addition, through the analysis of the influence of PCB thickness to the natural frequency, provides reference for the design of the PCB.

\section{Reference}

[1] Li Chunyang, Chen Xun,Tao Junyong, etc. Study on Printed Circuit Board Reliability under Vibration Stress Based on Modal Analysis[J]. Journal of North University of China(Natural Science Edition),2007,28(2):156-160.

[2] Cheng Shixun. The Modal Analysis and Vibration Reliability Research on Printed Circuit Board with Integrated Circuit Component[D]. The University of Electronic Science and Technology, 2005.

[3] Li Jiankang, Xu Ling, Cai Yixi, etc. Research on the Modal Test of a LQ6105 Diesel Engine Body and its Static and Dynamic Finite Element Analysis[J], Transactions of CSICE, 1999,17(2):132-135.

[4] Pitarresi J M, Primavera A A. Comparison of modeling techniques for the vibration analysis of printed circuit cards[J]. ASME Journal of Electronic Package,1992,114(4):378-383.

[5] Yi Jianwei, Zhou Yun, Zhang Wangxi. Modal Experiment on Elastic Foundation Slab and Identification of Dynamic Foundation Parameters[J]. China Journal of Highway and Transport,2007,20(2):1-6. 